\title{
MIGRAÇÃO INVOLUNTÁRIA COMO FATOR DE RISCO À SAÚDE MENTAL
}

\author{
Lucienne Martins-Borges*
}

\begin{abstract}
O deslocamento forçado de pessoas é um dos fenômenos que podem ser relacionados a conflitos políticos e sociais, guerras e catástrofes naturais. Essas partidas não-planejadas são frequentemente acompanhadas de sofrimento psicológico diretamente ligado às perdas e ao traumatismo ao qual foram submetidas. Este artigo tem por objetivo apresentar observações realizadas no Serviço de Atendimento Psicológico Especializado aos Imigrantes e Refugiados (Sapsir), da Universidade Laval, Canadá. O trabalho clínico desenvolvido com pessoas oriundas de mais de 40 nacionalidades permitiu ressaltar quadros psicopatológicos mais frequentemente observados e estabelecer períodos críticos do processo de adaptação que tendem a expor tais pessoas a uma maior vulnerabilidade psicológica. Essas observações permitem pensar em políticas de acolhimento e de atendimento (saúde e social) de refugiados, que permitam prevenir um maior sofrimento psíquico e contribuir para uma melhor adaptação.
\end{abstract}

Palavras-chave: Psicologia Intercultural; Psicologia Cultural; Refugiados.

\section{Introdução}

De acordo com o Censo Demográfico de 2010,1 havia no Brasil 92.529 imigrantes estrangeiros que 5 anos antes residiam em outro país. Esse número não inclui os 175.766 brasileiros retornados. No Censo de 2000 foram registrados 55.718 estrangeiros que moravam 5 anos antes em outro país. Portanto, em 10 anos, o aumento foi de $66 \%$. Os dados do Censo não captam o fluxo de imigrantes haitianos desencadeado pelo terremoto de janeiro de 2010. De acordo com o Ministério da Justiça, em janeiro de 2012 foi concedida a "residência humanitária" a cerca de 5 mil deles. Outros

\footnotetext{
* Doutora em Psicologia, Professora do Departamento de Psicologia da Universidade Federal de Santa Catarina. Email: lucienne.borges@ufsc.br. Florianópolis/Brasil.

${ }^{1}$ INSTITUTO BRASILEIRO DE ESTATÍSTICA E GEOGRAFIA. Censo 2010.
} 
608 receberam essa concessão em abril. O governo brasileiro adotou em janeiro do mesmo ano uma política de concessão de 1.200 vistos anuais para haitianos, o que representa a potencial entrada de 1.200 famílias poer ano. ${ }^{2}$

O governo concedeu em 2009 "anistia" a cerca de 45 mil estrangeiros que estavam em situação irregular no Brasil. Desses, em janeiro de 2012, 40\% já haviam obtido residência permanente. Depois de quatro anos de residência permanente, o estrangeiro pode pedir naturalização. Segundo o Departamento de Estrangeiros do Ministério da Justiça, a maioria dos que solicitaram residência permanente é formada por bolivianos, chineses e paraguaios. Do total, 44\% (7.942) têm entre 19 e 30 anos e 61\% (cerca de 11.000) são homens, o que sugere o perfil de pessoas que vieram para trabalhar no Brasil.

O deslocamento dessas populações, e mais particularmente o movimento de grupos de refugiados, pode ser considerado como uma das consequências dos conflitos políticos, sociais e étnicos da atualidade mundial, assim como de catástrofes naturais. No que se refere às Américas, os Estados Unidos, a Venezuela e o Canadá são os três países com o maior número de pessoas acolhidas com o estatuto de refugiado: 265.000, 202.000 e 165.000 respectivamente. Em 2009, dos 4.500 refugiados (reconhecidos) em solo brasileiro, 64\% vinham da África (Congo e Angola) e 23\% da América do Sul (principalmente da Colômbia). Desse total de refugiados, 33\% são mulheres. ${ }^{3}$ Cabe ressaltar que consideramos aqui o refugiado como toda:

pessoa que, em razão de fundados temores de perseguição devido à sua raça, religião, nacionalidade, associação a determinado grupo social ou opinião política, encontra-se fora de seu país de origem e que, por causa dos ditos temores, não pode ou não quer regressar ao mesmo. ${ }^{4}$

Os refugiados, pelo caráter involuntário e repentino de seu deslocamento, transportam consigo muito pouco do que até então caracterizava sua identidade: hábitos, relações, status profissional e social, residência. Essas partidas não-planejadas, e muitas vezes não-desejadas, são frequentemente tomadas por um sofrimento psicológico diretamente ligado ao traumatismo ao qual foram submetidos no período pré-migratório e migratório (violências diversas, tortura, testemunhas e vítimas de massacres, morte de parentes, amigos, etc). Quando nos referimos aqui ao caráter involuntário dessa categoria de migração, salientamos que o refugiado - contrariamente ao migrante

${ }^{2}$ Cf. MINISTÉRIO DA JUSTIÇA. Estrangeiros. Aprovada concessão de vistos especiais para haitianos.

${ }^{3}$ UNHCR. 60 years and still counting. Global Trends 2010.

${ }^{4}$ ACNUR BRASIL. Manual de procedimentos e de critérios para determinar a condição de refugiado. De acordo com a Convenção de Genebra 1951 e o Protocolo de 1967 relativos ao Estatuto dos Refugiados. 
voluntário -, além de não ter planejado sua partida, também não planejou sua transição entre o país de origem e o de acolhida, além de não ter se projetado nesse novo lugar. Essa distinção não deve ser considerada apenas como um detalhe que distingue os dois tipos de migração. Nessa distinção também estão implícitas outras diferenças. Dentre elas, deve-se destacar o tipo de trabalho psíquico que o processo de migração involuntária exigirá da pessoa, assim como o impacto desse trabalho sobre a saúde mental do refugiado.

\section{Cultura e Saúde Mental}

Ao se pensar no refugiado, no migrante, faz-se necessária a realização de uma breve reflexão acerca da função exercida pela cultura - principalmente em relação à saúde mental - na vida dessas pessoas. A definição de "cultura" varia de acordo com as disciplinas, as abordagens. O objetivo desse artigo não consiste em realizar uma discussão sobre a cultura, mas em compreender a relação entre cultura, mundo psíquico e saúde mental, a partir de uma perspectiva cultural vinculada à psicologia - mais precisamente à etnopsiquiatria pensada e praticada por Tobie Nathan e Marie-Roso Moro.

Para Tobie Nathan", a cultura corresponderia ao "mapa mental" que permite a cada membro de uma sociedade movimentar-se, pensar e trabalhar; enfim, viver evitando medo e perplexidade. Desse modo, o mundo interno (mundo psíquico) e o mundo externo (cultura) podem se comunicar, encontrar mutuamente um sentido, uma vez que possuem uma mesma linguagem. Compreende-se a cultura como lugar de construção da linguagem simbólica do sujeito - o que inclui também a língua - e como parte integrante de seu desenvolvimento psíquico. ${ }^{6}$

O migrante é aquele sujeito que se encontra fora da zona geográfica cultural na qual se constituiu. A comunicação entre o mundo externo e o mundo interno se encontra - pelo menos temporariamente - abalada. Essa ausência de comunicação pode gerar vulnerabilidade psíquica para o migrante - e principalmente para os refugiados - que se deparam com a experiência do non-sens, da falta de compreensão, de defesa/proteção que poderia lhe proporcionar sua cultura de origem - por mais destruidora que tenha sido. $\mathrm{O}$ propósito dessa observação não é o de isolar, de reduzir o sujeito exclusivamente ao mundo cultural que o constituiu, mas sim assinalar a importância da cultura e de sua lógica na constituição psíquica de todo o sujeito, e, por conseguinte, da sua relação com a saúde mental - sintomatologia, etiologia, tratamento - dessas pessoas.

\footnotetext{
${ }^{5}$ NATHAN, Tobie. La Folie des autres. Traité d'ethnopsychiatrie clinique.

${ }^{6}$ MORO, Maire-Roso. Psychothérapie transculturelle de l'enfant et de l'adolescent.
} 


\section{Exílio e elaborações psíquicas}

Entre o início do conflito no país de origem e a adaptação no país de acolhimento, uma série de acontecimentos pode vir a dificultar o bem-estar psicológico de pessoas que vivem o exílio. É necessário recomeçar - e muitas vezes em um país do qual até então ignoravam a existência - sem o domínio da língua, sem documentos que comprovem seus saberes e habilidades, sem todos os membros da família, sem os referentes culturais que até então o caracterizavam como pertencendo a um determinado grupo, com hábitos definidos e repletos de sentidos e representações simbólicas.

O deslocamento forçado implica em perdas e rupturas que não puderam ser preparadas e elaboradas. O refugiado, ao chegar ao país de acolhimento, carrega consigo um sentimento de fracasso - por ter tido que renunciar a sua continuidade existencial - acompanhado de uma certa nostalgia de um tempo em que ele era "feliz", em sua terra natal. Ao mesmo tempo, ele não consegue se projetar no país de acolhimento. Esse país, muitas vezes descoberto nos dias que antecedem sua migração, quando informado das possibilidades de refúgio, não pode ser desejado, imaginado; o refugiado não tem a oportunidade de se ver, em um futuro próximo ou distante, nesse novo país.

O refugiado é então aquele que tenta se projetar em um outro lugar, mas psiquicamente é tomado pelo passado e por tudo que caracteriza seu país de origem. Percebe-se aqui uma dupla dificuldade: o refugiado deve se reatualizar como sujeito em um país que não foi desejado - o que requer uma energia psíquica importante - enquanto se vê fragilizado pelas marcas do trauma. Cabe ressaltar que, pela natureza dos conflitos que levam aos deslocamentos dos refugiados - guerras, genocídios, tortura, etc. -, o sujeito carrega consigo o fracasso individual, mas também coletivo. Não foi ele - ou sua família - que foi atingido pelo conflito; mas é toda uma comunidade, um grupo étnico, um país, etc.

O período que precede a chegada ao país de acolhimento tende, para um número importante de pessoas, a aumentar essa vulnerabilidade psíquica. Assim, os traumatismos do exílio são muitas vezes agravados por fatores que ocorrem após a imigração, como a lentidão administrativa, os obstáculos à reconstrução de uma vida profissional e familiar, dificuldades em relação à língua, diferenças culturais, mudanças e inversão de papéis sociais (os pais passam, com frequência, da função de protetores à de dependentes), etc. Essas dificuldades geralmente demandam um acompanhamento psicossocial e psicológico.

Apesar de as políticas públicas estarem cada vez mais atentas à adaptação de seus recursos (financeiros e humanos) para um melhor acolhimento dos refugiados, pode-se perceber que, durante as etapas do processo de adaptação 
ao país de acolhimento ${ }^{7}$, o refugiado se depara com certas limitações quando se dirige às instituições de saúde e de assistência social, como clínicas médicas, centros de saúde, hospitais, centros de referência, associações comunitárias, etc. O contato com esses profissionais muitas vezes tem como consequência um agravamento do quadro clínico apresentado, além de um aumento das dificuldades encontradas ao longo do processo de adaptação. Como explicar o sofrimento, seja ele físico ou psicológico, quando o paciente e o profissional não falam a mesma língua? Partindo do princípio de que a língua materna é portadora de representações e organizações simbólicas formadoras da identidade, ${ }^{8}$ como poder falar do que se sente, do mal-estar, em uma língua cujas representações culturais diferem daquelas do paciente? Como oferecer, dentro do setting terapêutico ocidental, o lugar que certas culturas reservam ao mundo invisível, aos saberes populares, às transmissões intergeracionais? E como poder expressar toda frustração em relação ao país adotivo a um profissional originário desse mesmo país?

São todas essas questões que levaram uma equipe de pessoas, no Québec, Canadá, a pensar um dispositivo clínico que viesse alcançar resultados terapêuticos semelhantes àqueles obtidos com pacientes originários da sociedade de acolhimento. No Canadá e no Estado do Québec, as políticas públicas asseguram o acesso aos serviços de saúde e à assistência social. Porém, os resultados obtidos - isto é, a adesão ao tratamento e a melhora do quadro clínico apresentado - eram significativamente diferentes do que se observava na população em geral. Essa observação - a da insatisfação em torno dos atendimentos realizados - era feita por profissionais da saúde (que se sentiam impotentes frente à complexidade do quadro clínico apresentado) e pelos pacientes (por meio de associações de imigrantes, que relatavam não se sentir compreendidos). Foi precisamente essa constatação que levou à organização de serviços especializados, como é o caso do Serviço de Atendimento Psicológico Especializado aos Imigrantes e Refugiados (Sapsir). O objetivo aqui é o de apresentar, de forma breve, o trabalho realizado pelo Sapsir, assim como algumas observações oriundas da prática terapêutica ali realizada.

\section{O Serviço de Atendimento Psicológico Especializado aos Imigrantes e Refugiados (Sapsir)}

O Serviço de Atendimento Psicológico Especializado aos Imigrantes e Refugiados (Sapsir) foi criado em agosto de 2000 e suas atividades são reali-

\footnotetext{
${ }^{7}$ Para maior conhecimento das etapas de inserção dos imigrantes em um novo país, consultar BERRY, John W. Migração, aculturação e adaptação.

${ }^{8}$ MESMIN, Claude; BA, Myriam. La langue maternelle comme outil thérapeutique dans la prise en charge des familles migrantes et de leurs enfants.
} 
zadas na clínica-escola do departamento de psicologia da Universidade Laval, Québec, Canadá. A origem do Sapsir está relacionada com interesses variados, mas sempre voltados aos processos de adaptação que poderiam trazer um maior bem-estar aos novos membros da sociedade canadense francófona (Québec). Assim, pesquisadores (Departamento de Psicologia da Universidade Laval), profissionais da saúde, gestores públicos (Agência da Saúde e dos Serviços Sociais da Capital Nacional ${ }^{9}$ ) e grupos de imigrantes e refugiados representados pelas organizações não-governamentais e associações se mostravam cada vez mais preocupados com o baixo nível de adesão aos tratamentos oferecidos pela rede pública de saúde e de assistência social. Além dessa preocupação, o Estado de Québec, com sua política de regionalização da imigração (que visa estimular a instalação dos novos imigrantes em outras cidades do Estado, além de Montreal), possibilitou um aumento do número de pessoas acolhidas. Essas pessoas são geralmente oriundas de regiões de conflito e, por conseguinte, portadoras de um sofrimento psicológico importante. O Estado de Québec tem uma população de aproximadamente 7.500.000 habitantes e acolhe entre 25.000 e 30.000 imigrantes (autônomos, refugiados, etc.). Considerando apenas a cidade onde são realizadas as atividades do Sapsir, a cidade de Québec, 1.500 a 2.000 imigrantes são acolhidos anualmente. Aproximadamente 50\% (de 800 a 900) do número total de imigrantes são refugiados, vindos principalmente dos países da Europa do Leste, da Colômbia, do Afeganistão, de Ruanda, do Congo, do Burundi e, mais recentemente, dos campos de refugiados situados no Paquistão e no Nepal. ${ }^{10}$

Desde 2000 o Sapsir é financiado pela Agência da Saúde e dos Serviços Sociais da Capital Nacional. Em 2004, foi reconhecido e financiado pelo Alto Comissariado para os Direitos Humanos (ACDH) da Organização das Nações Unidas (ONU) por se tratar de um dos programas canadenses que oferecem atendimento psicológico a vítimas diretas e indiretas de tortura. De forma breve, pode-se dizer que se trata de uma clínica de psicologia, uma clínica do vínculo e da mediação entre o antes (país de origem) e o depois (país de acolhimento), onde é exercida uma atividade terapêutica, dispensada por uma equipe de psicólogos e doutorandos em psicologia, geralmente de origem cultural diferente e que falam, no mínimo, além de sua língua materna, o francês. ${ }^{11} \mathrm{O}$ Sapsir acolhe, igualmente, em seu grupo de

\footnotetext{
${ }^{9}$ O equivalente das Secretarias Estaduais de Saúde.

10 MARTINS-BORGES, Lucienne; POCREAU, Jean-Bernard. Serviço de atendimento psicológico especializado aos imigrantes e refugiados: interface entre o social, a saúde e a clínica. IDEM. Reconhecer a diferença: o desafio da etnopsiquiatria.

11 POCREAU, Jean-Bernard; MARTINS-BORGES, Lucienne. A identidade como fator de imunidade psicológica: contribuições da clínica intercultural perante as situações de violência extrema.
} 
terapeutas, profissionais oriundos de outras disciplinas, como enfermagem, medicina, serviço social, etc. Desde o início de suas atividades, o Sapsir já recebeu pacientes de cerca de 40 países, em sua maioria refugiados. Os atendimentos são oferecidos a indivíduos, casais ou famílias.

\section{a) A prática clínica do Sapsir}

Os profissionais do Sapsir trabalham em grupo - grupo de terapeutas - dentro de um dispositivo específico, no qual uma atenção particular é dada à dimensão cultural do transtorno e de sua expressão sintomática, sem negligenciar, no entanto, a análise dos funcionamentos psíquicos. O dispositivo clínico é inspirado nos modelos propostos por Tobie Natha ${ }^{12}$ e MarieRoso Moro ${ }^{13}$. Quando possível, é solicitada a colaboração de um mediador linguístico e cultural (geralmente chamado de intérprete), que assegura a tradução da língua. Também é solicitada ao mediador cultural a tradução de elementos culturais que podem vir a fornecer subsídios ao trabalho terapêutico (como informações sobre os ritos, as filiações e afiliações, as práticas religiosas, as compreensões sobre saúde mental, etc.). Com a presença do mediador cultural, procura-se favorecer a expressão da experiência vivida e dos afetos na língua materna e oferecer um espaço significativo aos dados culturais e às representações sociais. Os mediadores culturais, na cidade de Québec, são capacitados e coordenados por uma ONG. Procura-se evitar mediadores que tenham vínculos familiares e sociais com os usuários e, na medida do possível, todo o processo terapêutico é realizado com a participação de um mesmo mediador cultural.

Em geral, as pessoas são encaminhadas ao Sapsir pelos profissionais da Saúde, da Assistência Social e pelas instituições de ensino (postos de saúde, hospitais, clínicas médicas, ONGs, escolas de introdução à língua francesa, escolas regulares, etc.). Quando a pessoa que encaminha o paciente imigrante ao Sapsir está disponível para acompanhá-lo, sua presença, no primeiro encontro, é de grande utilidade. Esse acompanhamento tem por objetivo, quase sempre, tranquilizar o paciente e validar sua confiança em uma situação na qual, uma vez mais, ele deverá expor sua história. ${ }^{14}$ Logo após a criação do Sapsir, nos primeiros meses, não era solicitado ao profissional o acompanhamento do paciente. Ao mesmo tempo, observava-se um número elevado de ausências ao primeiro encontro (sem que o paciente entrasse em contato). Após a sistematização do acompanhamento, a presença dos

\footnotetext{
${ }_{12}$ NATHAN, La Folie..., op. cit.; IDEM. L'influence qui guérit.

${ }^{13}$ MORO, op. cit.

${ }^{14}$ MARTINS-BORGES, POCREAU, op. cit.
} 
pacientes ao primeiro encontro - e nos encontros subsequentes - aumentou, o que reforça a percepção da importância do trabalho em torno dos vínculos com essas pessoas confrontadas a múltiplas rupturas.

A referência às representações culturais, às lógicas e às hipóteses etiológicas tradicionais, aos ritos de iniciação, de filiação e de afiliação é portadora de um sentido para o sujeito. As intervenções dos co-terapeutas passam pela mediação do terapeuta principal, o qual as julgará como sendo pertinentes ou não. Nenhuma intervenção é feita diretamente pelos co-terapeutas. Eles se dirigem ao terapeuta principal - e o paciente é testemunha dessa formulação -, que decidirá sobre a pertinência da intervenção. A formulação dessas intervenções pode assumir a forma de questionamentos, de observações ou de proposições de compreensão ${ }^{15}$. Essa passagem pela cultura do paciente, através de suas elaborações e da presença do mediador cultural, mostra-se eficaz, pois permite ao paciente a retomada de contato com sua identidade e permite a construção de um novo vínculo com suas origens.

O trabalho clínico realizado pelo dispositivo terapêutico do Sapsir passa por três dimensões principais $^{16}$, com o objetivo de acompanhar e facilitar as elaborações essenciais implicadas no trabalho psíquico do refugiado:

1. As que se referem às perdas e separações: trabalho sobre os vínculos de origem, vínculos de afiliação e vínculos atuais;

2. As que se referem à identidade: trabalho sobre as dimensões da identidade relacionada com a alteridade;

3. As que se referem à projeção de si mesmo, no tempo e no espaço: trabalho sobre a coerência e o sentido das experiências passadas e atuais.

O dispositivo é específico e especializado, composto de um grupo de terapeutas (e não um grupo de pacientes) e que procura constantemente o encontro entre normas, práticas e compreensões de dois mundos: o mundo que traz o paciente por meio de sua identidade e suas elaborações e o outro mundo, aquele que representa a sociedade de acolhimento. Todo o trabalho será voltado à tentativa de restabelecer os vínculos supracitados, acentuando as etapas que serão necessárias ao processo de adaptação e de integração na sociedade de acolhimento (e tudo que se refere a ela).

Desde o início de suas atividades, em 2000, o SAPSIR recebeu mais de 200 pessoas, oriundas de diversas comunidades culturais. A maioria é constituída por refugiados $(82,2 \%)$, mulheres $(57,2 \%)$, geralmente acompanhados por outros membros da família $(87,2 \%)$. Dentre as razões

${ }^{15}$ Ibidem.

${ }^{16}$ Ibidem. 
porque imigraram para o Canadá, destacam-se: guerra, genocídio, conflitos políticos ou religiosos. Com relação às consultas, observou-se que mais de 57\% das pessoas compareceram ao SAPSIR nos dois primeiros anos de imigração: 25\% nos primeiros 6 meses seguintes à chegada ao país deacolhimento e $11,7 \%$, nas primeiras semanas. O SAPSIR recebeu pessoas de todas as faixasetárias, que consultaram individualmente, com o parceiro(a) ou com a família. No que se refere àidade, 58\% tinham entre 26 e 45 anos, 19\% eram crianças e adolescentes, 15\% tinham entre 46 e 60 anos e $8 \%$ eram jovens adultos. Quanto ao país de origem dessas pessoas, destacam-se: Colômbia, Bósnia, República Democrática do Congo, Afeganistão e Ruanda.

\section{Consequências psicológicas do processo migratório}

Conforme mencionado, o refugiado é aquele que traz consigo marcas de uma história de traumatismos, que o fragilizam e o tornam vulnerável psicologicamente. Devido à dificuldades encontradas, o processo migratório em si pode ser vivenciado como um novo traumatismo, um traumatismo do exílio, com consequências psicológicas importantes, particularmente a perda da coesão e da continuidade de si.

Devido à ausência da cultura fundadora, percebe-se uma ruptura da comunicação entre o mundo externo e o mundo interno, uma perda de fluidez dos mecanismos mentais, sentidos diferentes para uma mesma realidade, normas sociais incompatíveis e uma incongruência entre o objeto idealizado e a realidade. As alterações na identidade social e afetiva (separação, divórcio, filiação, trabalho, etc.) ocorridas durante o processo migratório fazem com que a migração seja então vivenciada como uma situação de vulnerabilidade psicológica, na qual os mecanismos de defesa se tornam menos eficazes. Além dessas situações que causam a vulnerabilidade, percebe-se que o contato específico com três tipos de instituições - de saúde, de educação e justiça - pode intensificar essa vulnerabilidade e levar a um sofrimento psíquico importante.

Essa alteração do sistema de valores pode ser acompanhada de sintomas típicos, e frequentemente observados na população em geral, de um sofrimento psicológico, que poderia ser designado pela categoria dos transtornos depressivos e ansiosos. Porém, observam-se tais sintomas sendo expressos de forma intensa e que tendem a se tornar crônicos pelos elementos culturais por eles representados. Alguns desses sintomas são a tristeza profunda, o desânimo, o isolamento social, conflitos com a cultura do novo país, etc. Ademais, uma série de queixas somáticas, isto é, sofrimentos físicos dos quais não se chega a um diagnóstico preciso (pois geralmente a "dor" sentida é 
uma expressão de um sofrimento psíquico), encontra-se presente no discurso do refugiado. O corpo, pela ausência da língua e da linguagem (modos de comunicação), assume o lugar da comunicação com o mundo externo. Além do diagnóstico tradicional do estresse pós-traumático, observa-se igualmente a presença significativa de quadros clínicos de ansiedade, de manifestações depressivas, de sintomas hipocondríacos e um aumento do consumo e abuso de álcool e drogas, acompanhadas ou não de passagens ao ato agressivas. Tais queixas parecem ser a expressão de uma dor vinda do interior, ocasionada por uma ruptura e por uma dificuldade de reconstrução de uma "nova" identidade. O quadro clínico apresentado impossibilita o investimento em novas atividades profissionais e sociais, o que dificultará o processo de integração.

\section{Considerações finais}

Os refugiados chegam ao Sapsir em momentos variados do processo migratório. Quando o encaminhamento é feito nos primeiros meses de sua chegada em Québec, o trabalho terapêutico possibilita - além do objetivo geral de um processo terapêutico - um acompanhamento durante as etapas iniciais da migração. Esse momento visa igualmente a prevenção de certas crises e do agravo do quadro clínico. Nessas situações, percebe-se uma melhor integração à sociedade de acolhimento, pois o refugiado poderá se investir nas atividades propostas, na elaboração do luto relacionado às perdas ocasionadas pelo exílio.

Alguns refugiados chegam à clínica depois de meses ou mesmo anos e a demanda muitas vezes é motivada por uma crise, desencadeada geralmente por novas modificações em seu contexto familiar (mortes, separações) ou problemas de saúde (o que o colocará em contato com as instituições de saúde e suas práticas). Nesses casos, a psicoterapia tende a durar (a média do número de sessões de todos os pacientes já atendidos é de 17 encontros) e os resultados se mostram menos satisfatórios, devido à complexidade do quadro clínico apresentado.

Outros pacientes nunca chegam à clínica, pois não sentiram a necessidade de uma escuta terapêutica; outros conseguiram essa escuta em grupos sociais e religiosos; outros passam pelo processo migratório sem dificuldades importantes. As condições da migração, os acontecimentos e encontros nos momentos iniciais da migração, as predisposições psicológicas individuais variam muito e determinam como se dará a integração. Hoje, depois de anos tentando mostrar a importância da saúde mental no processo de migração, o Sapsir passou a representar um dos serviços de saúde que garantem o direito dos cidadãos refugiados a um atendimento especializado. Esse direito é garantido nas novas Políticas Públicas de Saúde e Serviços Sociais do Estado do Québec, por meio da recomendação de se levar em conta as características culturais e linguísticas das 
comunidades etnoculturais. Assim, o Sapsir se inscreveu como uma entidade relacionada à categoria Outros colaboradores: Serviços oferecidos pelas organizações comunitárias dedicadas às comunidades etnoculturais. O trabalho realizado pelos profissionais do Sapsir só é possível porque ele conta com a colaboração das mais diversas instituições vinculadas ao Estado do Québec: de saúde, de educação, de assistência social, da justiça, etc.

A história do acolhimento de refugiados no Estado de Québec é recente. O que possibilitou pensar novas políticas e atingir resultados favoráveis foi o fato de todos os atores terem reagido às dificuldades encontradas já no início do aumento da imigração. A partir do momento em que nos dispomos a acolher, a nos tornarmos um país de imigração - como é o caso do Brasil -, precisamos nos apoiar em modelos existentes e pensar como construir um espaço para os refugiados que são acolhidos pelo Estado brasileiro. Esse espaço deve ir além de um espaço de vida e de trabalho. Precisamos repensar nossas práticas e pensar em uma forma de garantir seus direitos à saúde - mental e física -, pois eles servirão de base a uma integração saudável.

\section{Bibliografia}

ACNUR BRASIL. Manual de procedimentos e de critérios para determinar a condição de refugiado. De acordo com a Convenção de Genebra 1951 e o Protocolo de 1967 relativos ao Estatuto dos Refugiados. ACNUR Brasil, 2004.

BERRY, John W. Migração, aculturação e adaptação. In DE BIAGGI, Sylvia; PAIVA, Geraldo José de (orgs.). Psicologia, E/Imigração e Cultura. São Paulo: Casa do Psicólogo, 2004, p. 29-45.

INSTITUTO BRASILEIRO DE ESTATÍSTICA E GEOGRAFIA, 2010. Disponível em: <http://www.ibge.gov.br/home/estatistica/populacao/censo2010/resultados_gerais_ amostra/default_resultados_gerais_amostra.shtm > . Acesso em: 06.07.2012.

MARTINS BORGES, Lucienne; POCREAU, Jean-Bernard. Serviço de atendimento psicológico especializado aos imigrantes e refugiados: interface entre o social, a saúde e a clínica. Estudos de psicologia, Campinas, v. 29, n. 4, dez. 2012.

- Reconhecer a diferença: o desafio da etnopsiquiatria. Psicologia em Revista, v. 15, n. 1, 2009, p. 232-245, 2009.

MESMIN, Claude; BA, Myriam. La langue maternelle comme outil thérapeutique dans la prise en charge des familles migrantes et de leurs enfants. In MESMIN, Claude; GUILLARD, Suzanne (orgs.). Psychothérapies des enfants de migrants. Grenoble: La Pensée Sauvage, 1995, p. 21-40.

MINISTÉRIO DA JUSTIÇA. Aprovada concessão de vistos especiais para haitianos. 2012. Disponível em: <http://portal.mj.gov.br/>. Acesso em: 06.07.2012.

MORO, Maire-Roso. Psychothérapie transculturelle de l'enfant et de l'adolescent. Paris: Dunod, 1998. 
NATHAN, Tobie. La Folie des autres. Traité d'ethnopsychiatrie clinique. Paris: Dunod, 1986. . L'influence qui guérit. Paris: Éditions Odile Jacob, 1994.

POCREAU, Jean-Bernard; MARTINS-BORGES, Lucienne. A identidade como fator de imunidade psicológica: contribuições da clínica intercultural perante as situações de violência extrema. Psicologia: Teoria e Prática, v. 11, n. 3, 2009, p. 224-236.

TREMBLAY, Margot. L'accessibilité et l'adaptation des services de santé et des services sociaux et psychosociaux aux personnes issues des communautés ethnoculturelles de la région de la Capitale-Nationale. Bilan 2002-2005 et Plan d'action régional 2006-2009. Québec: Agence de la santé et des services sociaux de la CapitaleNationale: 2006.

UNHCR - United Nations High Commissioner for Refugees. 60 years and still counting. UNHCR: Global Trends 2010. Geneva: UNHCR, 2011.

\section{Abstract}

\section{Involuntary migration as a risk factor for mental health}

The forced displacement of people, known as refugees or involuntary immigrants, is one of the phenomena related to political and social conflicts, wars and natural catastrophes. These unplanned and often undesired departures are often followed by psychological suffering directly related to the losses and to the trauma to which they have been exposed before and after the migration. Those difficulties can be represented by bureaucratic barriers, obstacles to the reconstruction of a professional and family life, communication difficulties, cultural differences, family roles' inversions and so on. This article's main goal is to present observations made at the Service of Specialized Psychological Attention for Immigrants and Refugees (Sapsir), at the Laval University, Québec, Canada. The clinical work developed with people from more than 40 nationalities has made it possible to highlight psychopathological symptoms more often observed, and establish critical periods in the adaptation process which tend to expose such people to a higher psychological vulnerability. These observations allow us to design policies for sheltering and (health and social) attention for refugees, making it possible to prevent a more serious psychic suffering and, consequently, to contribute for a better adaptation and integration.

Keywords: Intercultural Psychology; Cultural Psychology; Refugees.

Recebido para publicação em 24/02/2013.

Aceito para publicação em 06/05/2013.

Received for publication in February, 24 $4^{\text {th }}, 2013$.

Accepted for publication in May, 06 ${ }^{\text {th }}, 2013$. 